\title{
Reversal of Multidrug Resistance by the Chinese Medicine Yiqi Jianpi Huaji Decoction and the Mechanism of Action in Human Gastric Cancer SGC7901/VCR Cells
}

\author{
Wei-Bing $\mathrm{Li}^{1}{ }^{1}$ Yang $\mathrm{Li}^{2}{ }^{2}$ Chen $\mathrm{Yu}^{1}{ }^{1}$ and Yong-Ming $\mathrm{He}^{1}$ \\ ${ }^{1}$ Department of Integrated Traditional and Western Medicine, Jiangsu Cancer Hospital, Baizi Ting, No. 42, Nanjing, \\ Jiangsu 210000, China \\ ${ }^{2}$ Department of Radiation Oncology, Cancer Center, Sun Yat-sen University, Guangzhou, Guangdong 510006, China
}

Correspondence should be addressed to Wei-Bing Li; 41186709@qq.com

Received 25 November 2014; Revised 6 January 2015; Accepted 6 January 2015

Academic Editor: Oliver Micke

Copyright (C) 2015 Wei-Bing Li et al. This is an open access article distributed under the Creative Commons Attribution License, which permits unrestricted use, distribution, and reproduction in any medium, provided the original work is properly cited.

\begin{abstract}
Yiqi Jianpi Huaji Decoction (YJHD), a traditional Chinese medicinal formula composed of twelve ingredients, has recently been reported to have a good clinical curative effect. The purpose of the present study was to evaluate the effects of YJHD on SGC7901/VCR gastric cancer cells and to elucidate the possible mechanism of action. First, the effects of a low dose of YJHD in combination with chemotherapeutic agents on SGC7901/VCR cells were assessed using the CCK-8 assay and flow cytometry, and the effects of YJHD on genes and proteins involved in drug resistance (MDR1, MRP, TUBB3, STMN1, and TS) were evaluated. Furthermore, transfection of SGC7901/VCR cells with siRNAs targeting these genes inhibited their expression, and the efficacy of vincristine against the cells was dramatically improved in vitro when these genes were silenced. These results demonstrate that lowdose YJHD inhibited cell proliferation, induced apoptosis, reversed MDR, and increased sensitivity to chemotherapeutic agents in vitro by downregulating P-gp, MRP, TUBB3, and STMN1 expression. MDR can be reversed by siRNAs targeting genes involved in MDR, and this strategy for cancer treatment should be evaluated in future studies.
\end{abstract}

\section{Introduction}

Stomach cancer was the cause of 738,000 deaths in 2008 , corresponding to approximately $9.7 \%$ of the total number of cancer-related deaths [1], and the incidence and mortality rates for stomach cancer are significantly higher in China than in the rest of the world [2]. The major factors responsible for the increased mortality and morbidity associated with gastric cancer are the progression of the disease and failure of chemotherapy caused by multidrug resistance (MDR) [3] via the overexpression of the MDR1 and MRP genes [4]. The major cause of MDR in tumor cells is the overexpression of a membrane-bound protein, P-glycoprotein (P-gp), and other members of the adenosine triphosphate (ATP) binding cassette $(\mathrm{ABC})$ transporter superfamily [5], which translocate a substrate from the intracellular compartment to the extracellular compartment, leading to a reduced intracellular concentration of the substrate and resistance to antineoplastic drugs [6]. The overexpression of P-gp and MRP is associated with a poor prognosis. In normal gastric tissue, P-gp and MRP mRNAs are either not present or are only slightly elevated [7], whereas P-gp and MRP overexpression is associated with MDR in gastric cancer [8-10].

However, several other mechanisms are also involved in the development of MDR in tumor cells, including alterations in drug targets (e.g., TUBB3, STMN1, and TS), the activation of detoxifying systems, the interruption of signaling pathways, and alterations in regulators involved in cell cycle control [6], and the above genes exhibit chemotherapy-related effects. A number of studies have confirmed that a high TS expression level contributes to the resistance to 5-Fu and a poor clinical outcome [11]. Several studies using drugs that target microtubules have also found that $\beta$-tubulin III (TUBB3) and stathmin 1 (STMN1) are directly related to the efficacy of chemotherapy [6]. Additionally, elevated TUBB3 expression is related to vincristine resistance and a short 
survival time $[7,8]$, and STMN1 affects the formation of the mitotic spindle, promoting microtubule depolymerization or preventing microtubule polymerization [8].

Herbal medicines are an important source of novel agents with pharmaceutical potential [9]. Modern pharmacological experiments have led to the use of herbal medicines for complementary and alternative therapy, and this approach has become increasingly popular, particularly in cancer patients who exhibit resistance after several chemotherapy treatments $[10,12]$. Considering the narrow therapeutic window of chemotherapeutic agents, synergistic or additive interactions may improve the outcome of a therapy and reverse long-term chemotherapy drug resistance. As a result of the variation in adjuvant components, each formula can have a different name, and the precise mechanisms of action of these formulae also remain to be addressed in studies investigating their clinical efficacy. One such formula, Yiqi Jianpi Huaji Decoction (YJHD), is currently under study in our laboratory. YJHD is a prescribed Chinese complex that contains the following twelve ingredients: Codonopsis pilosula, Astragalus membranaceus, Atractylodes macrocephala koidz, Radix angelica, sinensis Radix paeoniae alba, Tangerine peel, Pinellia tuber, Zedoary, Rhizoma sparganii, Salvia chinensis, licorice, and Oldenlandia diffusa. YJHD shows good effect in clinical efficacy, and three components (Salvia chinensis, Zedoary, and Oldenlandia diffusa) exhibit potential anticancer activity and restore the sensitivity of MCF-7/ADR and A549/Taxol cells, modulating the MDR phenotype and the function of P-gp in vitro $[13,14]$. Oldenlandia diffusa extracts exert antiproliferative effects and induce apoptosis in human breast cancer cells [15]. Additionally, the individual use of other YJHD components has been reported in China and was found to strengthen the immune system, improve appetite, and act as antiangiogenesis and as an anticonvulsant [16]. However, the potential role of this formula in cancer therapy has not yet been clearly addressed by modern science. To further elucidate mechanisms that may be involved in the interaction between YJHD and chemotherapeutic agents, we also investigated apoptosis levels and the expression of chemotherapeutic agent resistance-related genes in gastric cancer cells after treatment with YJHD and chemotherapeutic agents singly and in combination.

RNAi is a fundamental cellular mechanism for silencing gene expression and can be used for the development of new drugs [17]. Accordingly, this study focused on the downregulation of MRP, MDR1, TUBB3, and STMN1 expression by siRNA. After transfection of siRNAs, silencing at the protein level was demonstrated by western blot analysis. Furthermore, we also examined the in vitro effects of siRNAmediated MRP, MDR1, TUBB3, and STMN1 suppression on the chemotherapeutic sensitivity of human SGC7901/VCR cell lines.

\section{Materials and Methods}

2.1. Preparation of YJHD Extract. All of the crude components, including $15 \mathrm{~g}$ Codonopsis pilosula, $15 \mathrm{~g}$ Astragalus membranaceus, $10 \mathrm{~g}$ Atractylodes macrocephala koidz, $10 \mathrm{~g}$ Radix angelica sinensis, $10 \mathrm{~g}$ Radix paeoniae alba, $6 \mathrm{~g}$
Tangerine peel, $10 \mathrm{~g}$ Pinellia tuber, $10 \mathrm{~g}$ Rhizoma sparganii, $10 \mathrm{~g}$ Zedoary, $30 \mathrm{~g}$ Salvia chinensis, $5 \mathrm{~g}$ licorice, and $30 \mathrm{~g}$ Oldenlandia diffusa, were purchased from the Jiangsu Provincial Hospital of Traditional Chinese Medicine (Nanjing, Jiangsu Province, China). First, a mixture of YJHD was homogenized with a Waring blender, then soaked in $10 \mathrm{~L}$ (10-fold of the plant) double-distilled water for $2 \mathrm{~h}$, and boiled for $1 \mathrm{~h}$. The cooled decoction was filtered through two layers of cotton gauze. The filtrates obtained from three cycles of the procedure were combined, and the filtered solution was concentrated into a residue in a vacuum evaporator and distilled into a liquid. The yield of the aqueous extract was $2.1 \mathrm{~g} / \mathrm{mL}$ based on the original amounts of the herbal ingredients.

The extract was reconstituted with sterile distilled water to prepare working solutions with final concentrations of 6 , $4,3,2,1,0.5$, and $0.25 \mathrm{mg} / \mathrm{mL}$ for the treatment of cancer cells. The quality control of the YJHD preparation, including the verification of the correct plant components, origin of production, and growth, harvesting, and processing, was performed according to the guidelines defined by Nanjing Herb Pharmaceutics Ltd. (Nanjing, Jiangsu Province, China).

2.2. Cell Lines and Cell Culture. The human gastric cell line SGC7901 was kindly provided by the center laboratory of Jiangsu Cancer Hospital, Nanjing, China. The human MDR gastric cancer cell line SGC7901/VCR was purchased from the Shanghai Institutes for Biological Sciences, Chinese Academy of Sciences (Shanghai, China). The cells were propagated in RPMI 1640 medium (GIBCO BRL, CA, USA) supplemented with $10 \%$ bovine serum, penicillin $(100 \mathrm{U} / \mathrm{mL})$, and streptomycin $(100 \mu \mathrm{g} / \mathrm{mL})$ at $37^{\circ} \mathrm{C}$ in a water-saturated atmosphere with $5 \% \mathrm{CO}_{2}$. For the SGC7901/VCR cell line, the medium contained an additional $1 \mu \mathrm{g} / \mathrm{mL}$ vincristine (Shenzhen Main Luck Pharmaceuticals).

2.3. Drugs. 5-Fluorouracil (5-Fu) was supplied by Jiangsu Hengrui Medicine Company (Jiangsu, China). Vincristine sulfate (VCR) was purchased from Shenzhen Main Luck Pharmaceuticals (Shenzhen, Guangdong, China). The dilutions of all of the reagents were prepared fresh before each experiment. An Annexin V-FITC flow cytometry detection kit was purchased from Nanjing KeyGEN Biotech. Co, Ltd. (Nanjing, Jiangsu, China).

2.4. Analysis of Cell Viability. The CCK8 assay was used to measure cell viability. Exponentially growing SGC7901/VCR cells $\left(100 \mu \mathrm{L}, 5 \times 10^{4}\right.$ cells $\left./ \mathrm{mL}\right)$ were seeded into 96 -well plates (Corning Incorporated, Corning, NY, USA). After $24 \mathrm{~h}$, the cells were cultured in an RPMI-1640 medium containing 10\% FBS and then treated with VCR or 5-Fu at concentrations ranging between 40 and $0.625 \mu \mathrm{g} / \mathrm{mL}$ as well as YJHD at concentrations between 6 and $0.5 \mathrm{mg} / \mathrm{mL}$. Then, we examined the combined effect of a low-dose YJHD and VCR or 5-Fu. The treatments were repeated three times at each concentration. The plates were then incubated in a humidified incubator (Sanyo, Osaka, Japan) at $37^{\circ} \mathrm{C}$ and $5 \% \mathrm{CO}_{2}$ for $48 \mathrm{~h}$. Subsequently, $2 \mathrm{~h}$ prior to measuring the absorbance, $10 \mu \mathrm{L}$ of CCK-8 solution was added to each well. The optical density was measured at an absorbance of $450 \mathrm{~nm}$ using a 
microplate reader (BioTek Instruments, Winooski, VT, USA). The rate of inhibition of cellular proliferation was calculated using the following formula: cellular proliferation inhibition rate $=\left(1-\right.$ mean $\mathrm{A}_{450}$ of experimental group $/$ mean $\mathrm{A}_{450}$ of control group) $\times 100 \%$. We chose to evaluate the chemotherapy drugs with the highest fold reversal levels.

2.5. Flow Cytometry. The effects of the evaluated concentrations of YJHD and chemotherapeutic drugs on apoptosis were determined by flow cytometry. The cells were seeded at $3 \times 10^{5}$ cells/well in six-well plates and incubated overnight. A low dose of YJHD $(0.5 \mathrm{mg} / \mathrm{mL})$ was added in combination with $0.625 \mu \mathrm{g} / \mathrm{mL}-2.5 \mu \mathrm{g} / \mathrm{mL}$ of $5-\mathrm{Fu}$, and the plates were incubated for $48 \mathrm{~h}$. Dimethylsulfoxide-treated cells (0.1\%) served as the control. The cells were collected and washed twice with $4^{\circ} \mathrm{C}$ PBS. The cells were then added to $500 \mu \mathrm{L}$ of binding buffer, and $5 \mu \mathrm{L}$ of Annexin V/FITC and $5 \mu \mathrm{L}$ of propidium iodide (PI) were then mixed. The experiments were performed in triplicate.

2.6. Cell Cycle Analysis. For the cell cycle analysis, SGC7901/ VCR cells were cultured in 6-well plates (at least $3.0 \times$ $10^{5}$ cells/well) in an RPMI-1640 medium containing $10 \%$ FBS and $100 \mathrm{U} / \mathrm{mL}$ of penicillin and streptomycin for $24 \mathrm{~h}$ and then treated with a low dose of YJHD $(0.5 \mathrm{mg} / \mathrm{mL})$ and $0.625 \mu \mathrm{g} / \mathrm{mL}$ of $5-\mathrm{Fu}$ for $48 \mathrm{~h}$. The cells were washed, collected, and fixed using $70 \%$ ethanol. Following that step, the cells were treated with TrisHCl buffer ( $\mathrm{pH}$ 7.4) containing 1\% RNase A (KeyGen Biotech Co., Ltd.) and stained with PI. Flow cytometry (FACSCalibur; Becton-Dickinson) was performed to determine the distribution of cells with varying DNA contents. Multicycle DNA content data were analyzed using cell cycle analysis software (KeyGen Biotech Co., Ltd.).

2.7. RNA Extraction and Real-Time Reverse Transcriptase$P C R$. Total RNA was extracted using Trizol (Invitrogen) according to the manufacturer's instructions. For mRNA analysis, real-time PCR was performed using the Power SYBR green PCR master mix (Applied Biosystems) with an ABI 7500 series PCR machine (Applied Biosystems), and the data were normalized to GAPDH expression and then further normalized to the negative control, unless otherwise indicated. Custom primers for TUBB3, STMN1, TS, MDR1, and MRP were synthesized by Ruian Biotech (GAPDH forward primer $5^{\prime}$-CCATGGAGAAGGCTGGGG-3' and reverse primer $5^{\prime}$-CAAAGTTGTCATGGATGACC-3'; TUBB3 forward primer $5^{\prime}$-GCCTGACAATTTCATCTTT- $3^{\prime}$ and reverse primer $5^{\prime}$-TCACACTCCTT CCGCACCA-3'; STMN1 forward primer $5^{\prime}$-AGAATACACTGCCTGTCGCTT G-3' and reverse primer $5^{\prime}$-AGGCACGCTTCTCCAGTT-3'; TS forward primer $5^{\prime}$-ACCTGAATCACAATC GAGCCA-3' $3^{\prime}$ and reverse primer $5^{\prime}$-TTG GATGCGGATTGTACCCT-3'; MDR1 forward primer $5^{\prime}$ CACGTCAGCCTTGGA CACAGA- $3^{\prime}$ and reverse primer $5^{\prime}$-CAA TGACTCCATCATCGAAACCAG- ${ }^{\prime}$; MRP forward primer $5^{\prime}$-TCTCTCCCGACATGACCGAGG- $3^{\prime}$ and reverse primer $5^{\prime}$-CCAGGAATATGCCCCGACTTC- $3^{\prime}$ ).
2.8. Western Blot Analysis. The proteins in the SGC7901/VCR cell culture supernatant were analyzed directly for STMN1, TUBB3, MDR1, MRP, and TS detection, and cell extracts were prepared in a suitable lysis buffer. In brief, each sample was mixed with loading buffer, separated by electrophoresis at a constant voltage and electrotransferred onto PVDF membranes (Millipore, Billerica, MA, USA). The membranes were incubated with a primary antibody at $4^{\circ} \mathrm{C}$ overnight, washed three times with TBS-T buffer, and incubated with a secondary antibody conjugated to horseradish peroxidase (Cell Signaling Technology, CST, Beverly, MA, USA) for $1 \mathrm{~h}$. After three washes, the blots were visualized using the enhanced chemiluminescence method (Millipore). Rabbit monoclonal antibodies against STMN1, TUBB3, MDR1, MRP, and TS were purchased from Abcam (Abcam, Cambridge, UK).

2.9. Transfection with siRNAs. Cells were seeded in 6-well plates and after, $24 \mathrm{~h}$ of growth, were then transfected with the indicated siRNAs (MDR1, MRP, STMN1, and TUBB3) using Lipofectamine RNAiMAX Reagent according to the manufacturer's protocol. Silencing was examined at $24 \mathrm{~h}$ after transfection by western blotting. The siRNA-transfected cells $(5 \times$ $10^{4} \mathrm{SGC7901/VCR} \mathrm{cells/mL)} \mathrm{were} \mathrm{plated} \mathrm{in} \mathrm{96-well} \mathrm{plates} \mathrm{and}$ treated with various concentrations of the test agents. After $48 \mathrm{hr}$, the $\mathrm{IC}_{50}$ values for vincristine in these cells were determined by the CCK- 8 assay. The siRNAs were synthesized by RiboBio (Guangzhou). The target sequences were as follows: MDR1 siRNA: $5^{\prime}$-AA GACATGACCAGGTATGCCT3'; MRP siRNA: $5^{\prime}$-CGAUGAAGACCAAGAC GUAUU3'; TUBB3 siRNA: $5^{\prime}$-UCUCUUCAGGCCUGACAAUTT3'; STMN1 siRNA: 5'-CAGTGGATTGTGTAGAGTGTA-3'. A negative control, $5^{\prime}$-UUCUCCGAACGUGUCACGUTT$3^{\prime}$, was also obtained from Dharmacon.

2.10. Statistical Analysis. All of the data are expressed as the mean $\pm \mathrm{SD}$. The results were analyzed using $t$-tests and analyses of variance with the SPSS 13.0 software. Values of $P<0.05$ were considered statistically significant.

\section{Results}

3.1. Inhibition of SGC7901/VCR and SGC7901 Cell Proliferation by YJHD. SGC7901/VCR and SGC7901 cells were treated with $0-6 \mathrm{mg} / \mathrm{mL} \mathrm{YJHD}$, and the results demonstrate the dose- and time-dependent inhibition of proliferation by YJHD (Figure 1(a)), inducing a greater than $90 \%$ reduction in the number of cells at the highest concentration $(6 \mathrm{mg} / \mathrm{mL})$. To evaluate whether YJHD increases the sensitivity of chemotherapeutic agents in an MDR gastric cancer cell line in vitro, we evaluated a nontoxic dose of YJHD combined with various concentrations of VCR and 5-Fu. The concentrations of the chemotherapeutic agents were selected according to their peak plasma concentrations in vivo: $40,20,10,5,2.5$, 1.25 , and $0.625 \mu \mathrm{g} / \mathrm{mL}$. The concentrations of YJHD were $6,4,2,1$, and $0.5 \mathrm{mg} / \mathrm{mL}$. The effects of the low dose of YJHD in combination with the chemotherapeutic agents on cell proliferation were measured using the CCK- 8 assay. As shown in Figures 1(b)-1(c), a concentration of $0.5 \mathrm{mg} / \mathrm{mL}$ of 


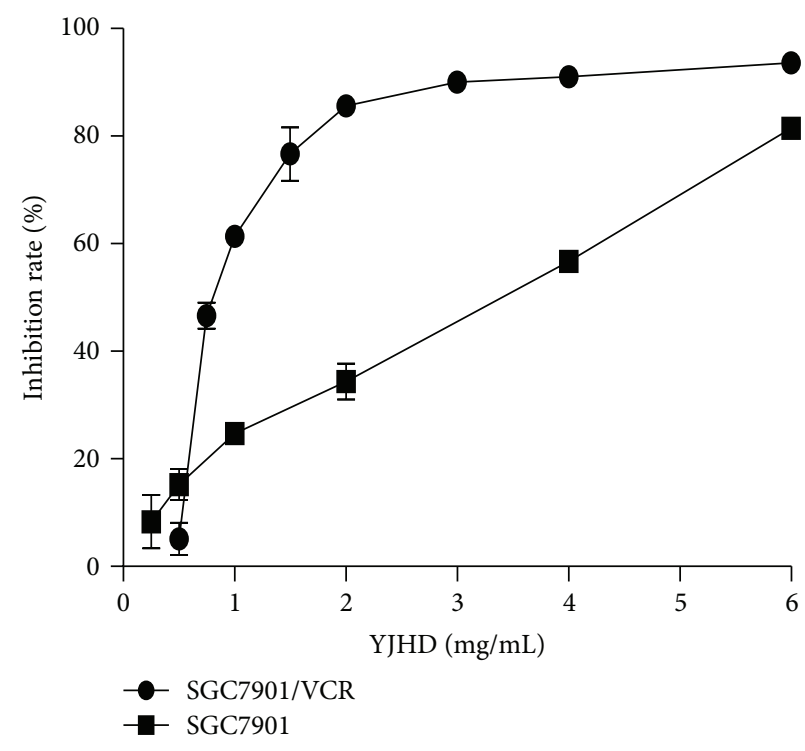

(a)

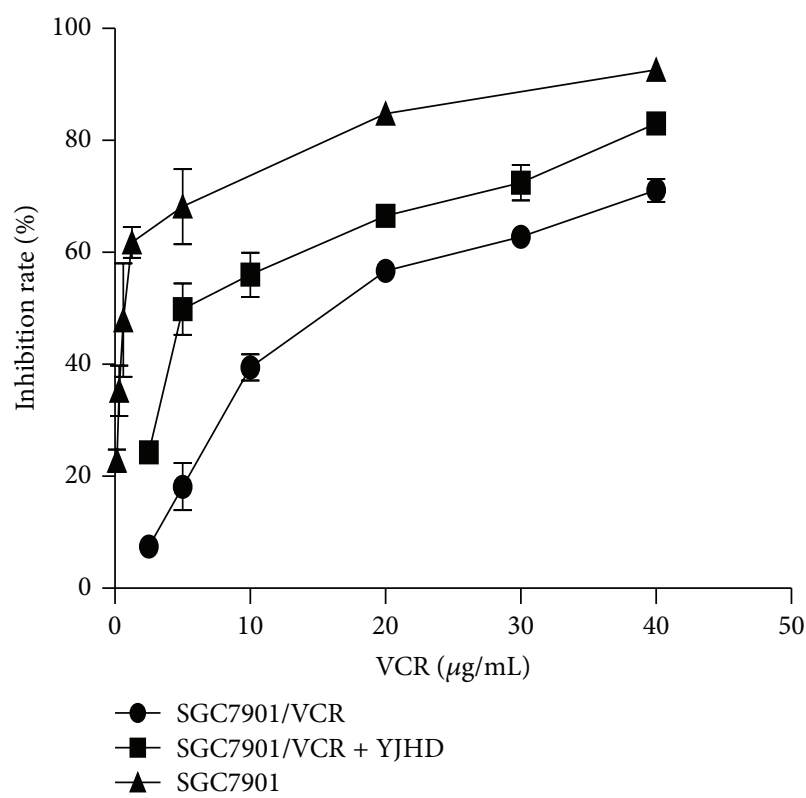

(b)

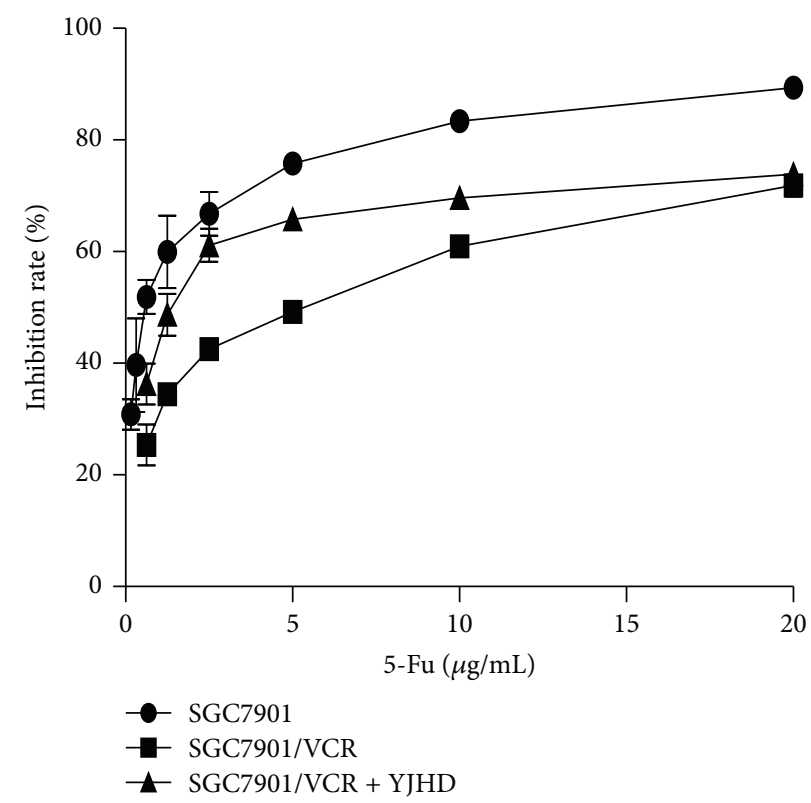

(c)

FIGURE 1: (a) Inhibition ratio of cell proliferation at increasing concentrations of YJHD in the SGC7901/VCR cell line. (b), (c) Cell inhibition ratios at increasing concentrations of VCR, 5-Fu, and VCR combined with $0.5 \mathrm{mg} / \mathrm{mL}$ of YJHD in SGC7901/VCR cells. The cell inhibition ratio was determined by the CCK- 8 assay.

YJHD increased the sensitivity of SGC7901/VCR cells to the chemotherapeutic agents and, to some extent, reversed MDR. The chemosensitivity of MDR cells to the chemotherapy drugs was measured by comparing $\mathrm{IC}_{50}$ values, expressed as $\mathrm{RF}$. The $\mathrm{IC}_{50}$ values of YJHD were $2.71 \pm 0.13$ and $0.86 \pm 0.046 \mathrm{mg} / \mathrm{mL}$, respectively, for the SGC7901 and SGC7901/VCR cell lines (Table 1). At less than or equal to $0.5 \mathrm{mg} / \mathrm{mL}$, YJHD did not cause any cytotoxicity to SGC7901/ VCR cells. Therefore, $0.5 \mathrm{mg} / \mathrm{mL}$ was chosen as the working concentration in the subsequent experiments. As expected, the SGC7901/VCR cells were more resistant to VCR. The $\mathrm{IC}_{50}$ values for 5-Fu and VCR in SGC7901 cells were $0.63 \pm 0.073$ and $0.84 \pm 0.08 \mu \mathrm{g} / \mathrm{mL}$, whereas the $\mathrm{IC}_{50}$ values for $5-\mathrm{Fu}$ and VCR were $4.378 \pm 0.12$ and $17.01 \pm 0.32 \mu \mathrm{g} / \mathrm{mL}$ for the SGC7901/VCR cells (Table 1). YJHD dose dependently increased the sensitivity of SGC7901/VCR cells to 5-Fu and VCR (Figures 1(b) and 1(c)). When administered at a nontoxic dose, YJHD shifted the $\mathrm{IC}_{50}$ values for 5 -Fu and VCR to $1.462 \pm 0.085$ and $7.29 \pm 0.24 \mu \mathrm{g} / \mathrm{mL}$, with RF values of $2.99 \pm$ 0.10 -fold and $2.33 \pm 0.10$-fold, respectively (Tables 2 and 3). 
TABLE 1: $\mathrm{IC}_{50}$ values $(\mu \mathrm{g} / \mathrm{mL})$ of anticancer drugs in gastric carcinoma cells.

\begin{tabular}{lccc}
\hline Cell line & 5-Fu $(\mu \mathrm{g} / \mathrm{mL})$ & $\mathrm{VCR}(\mu \mathrm{g} / \mathrm{mL})$ & YJHD $(\mathrm{mg} / \mathrm{mL})$ \\
\hline SGC7901 & $0.63 \pm 0.073$ & $0.84 \pm 0.08$ & $2.71 \pm 0.13$ \\
SGC7901/VCR & $4.378 \pm 0.12$ & $17.01 \pm 0.32$ & $0.86 \pm 0.046$ \\
RI & 6.94 & 20.25 &
\end{tabular}

Reversal factors (RFs) were calculated according to the following equation: $\mathrm{RF}=\mathrm{IC}_{50}$ antitumor drug alone $/ \mathrm{IC}_{50}$ antitumor drug + modulator.

TABLE 2: Magnitude of the reversal of multiple drug resistance by a low dose of YJHD.

\begin{tabular}{|c|c|c|}
\hline Cell line & $5-\mathrm{Fu}(\mu \mathrm{g} / \mathrm{mL})$ & $\begin{array}{c}5-\mathrm{Fu}+0.5 \mathrm{M} \text { YJHD } \\
(\mu \mathrm{g} / \mathrm{mL})\end{array}$ \\
\hline SGC7901/VCR & $4.378 \pm 0.12$ & $1.462 \pm 0.085$ \\
\hline $\begin{array}{l}\mathrm{RF}\left(5-\mathrm{Fu} \mathrm{IC} \mathrm{I}_{50} / 5-\mathrm{Fu}+\mathrm{YJHD}\right. \\
\left.\mathrm{IC}_{50}\right)\end{array}$ & & $2.99 \pm 0.10$ \\
\hline
\end{tabular}

TABLE 3: Magnitude of the reversal of multiple drug resistance by a low dose of YJHD.

\begin{tabular}{|c|c|c|}
\hline Cell line & $\operatorname{VCR}(\mu \mathrm{g} / \mathrm{mL})$ & $\begin{array}{c}+0.5 \mathrm{M} \text { YJHD } \\
(\mu \mathrm{g} / \mathrm{mL})\end{array}$ \\
\hline SGC7901/VCR & $17.01 \pm 0.32$ & $7.29 \pm 0.24$ \\
\hline $\mathrm{RF}\left(\mathrm{VCR} \mathrm{IC}_{50} / \mathrm{VCR}+\mathrm{YJHD} \mathrm{IC}_{50}\right)$ & & $2.33 \pm 0.10$ \\
\hline
\end{tabular}

However, treatment with YJHD did not significantly affect the drug sensitivity of SGC7901 cells.

3.2. Apoptosis in SGC7901/VCR Cells Induced by YJHD in Combination with Chemotherapeutic Drugs. Apoptosis was measured using flow cytometry. The apoptosis ratios in the control group were $7.39 \pm 1.25 \%$ after a $48 \mathrm{~h}$ treatment with $0.5 \mathrm{mg} / \mathrm{mL}$ YJHD. The apoptosis ratios for the YJHD and 5Fu groups were significantly increased compared to the 5$\mathrm{Fu}$ single-drug group $(P<0.05)$. These results indicate a dose-dependent effect on apoptosis in SGC7901/VCR cells $(P<0.05$; Figure 2), confirming the apoptotic and inhibitory effects of a low dose of YJHD when administered in combination with $5-\mathrm{Fu}$ on the growth of MDR gastric cancer SGC7901/VCR cells.

3.3. Enhancement of 5-Fu-Induced S-Phase Arrest in SGC7901/ VCR Cells by YJHD. In general, agents that induce cytotoxicity by inhibiting DNA synthesis (e.g., 5-Fu) arrest the cell cycle at $S$ phase [18]. As expected, at concentrations equal to $0.625 \mu \mathrm{g} / \mathrm{mL}$, 5-Fu-induced S-phase arrest. Although a low dose of YJHD $(0.5 \mathrm{mg} / \mathrm{mL})$ did not affect the cell cycle when administered by itself, treatment with YJHD in combination with 5 -Fu induced a significant S-phase arrest in up to $50.62 \pm 0.81 \%$ of the cells (Figure 3 ). These results suggest that YJHD enhanced 5-Fu-induced S-phase arrest, which may be attributed to its effect on drug resistance.

3.4. Influence of YJHD on the Expression of mRNA and Protein Encoding Chemotherapeutic Agent Resistance-Related Genes. To investigate the mechanisms underlying the synergistic
TABLE 4: Effect of siRNAs on the sensitivity of SGC7901/VCR tumor cells to chemotherapeutic drugs (vincristine) after transfection.

\begin{tabular}{lcccc}
\hline Drug & \multicolumn{4}{c}{$\mathrm{IC}_{50}(\mu \mathrm{g} / \mathrm{mL})$} \\
\hline \multirow{2}{*}{ Vincristine } & STMN1 & TUBB3 & MDR1 & MRP \\
& siRNA & siRNA & siRNA & siRNA \\
\hline $17.01 \pm 0.32$ & $7.13 \pm 1.15^{*}$ & $5.05 \pm 0.29^{*}$ & $1.77 \pm 0.38^{*}$ & $2.69 \pm 0.29^{*}$ \\
\hline
\end{tabular}

Cells were plated in 96-well multiwell plates. After $24 \mathrm{hr}$ of transfection, the cells were exposed to various concentrations of cytotoxic drugs for 2 days. After CCK- 8 was added, the absorbance in individual wells was determined at $450 \mathrm{~nm}$, and the $\mathrm{IC}_{50}$ was calculated.

The results represent the mean \pm SD of three separate experiments.

${ }^{*} P<0.05$ compared with control.

interaction between a low dose of YJHD and 5-Fu or VCR, we hypothesized that YJHD might affect the expression of chemotherapeutic agent resistance-related genes, that is, $M D R 1, M R P$, TS, STMN1, and TUBB3, by influencing their sensitivity to $5-\mathrm{Fu}$ and VCR. We first found that the gene expression of MDR1 and MRP in SGC7901/VCR cells is higher than that in SGC7901 cells. After incubating the cells with YJHD at their respective $\mathrm{IC}_{40}$ values for $48 \mathrm{~h}$, the levels of mRNA expression of these genes in SGC7901/VCR cells were assessed by real-time PCR. As shown in Figure 3, the levels of MDR1, MRP, TUBB3, and STMN1 were significantly downregulated by YJHD treatment, though YJHD did not downregulate the expression of TS. Similar results were obtained by western blotting, indicating that the expression levels of P-gp, MRP, TUBB3, and STMN1 were strongly positive in SGC7901/VCR cells for $48 \mathrm{~h}$. The expression levels were slightly positive in cells treated with $0.5 \mathrm{mg} / \mathrm{mL}$ of YJHD for $48 \mathrm{~h}$ (Figure 4), with very little effect on TS. These results demonstrate that YJHD decreased the expression of P-gp, MRP, TUBB3, and STMN1 in SGC7901/VCR cells and increased the antitumor effects of chemotherapeutic drugs by inhibiting their expression.

The stable knockdown of oncogenic STMN1, TUBB3, MRP, and MDR1 by siRNA significantly reversed the drug resistance of SGC7901/VCR cells in vitro.

Thus, to investigate the possible effects of knockdown of these genes in vitro, all four were downregulated in the SGC7901/VCR cell line (Figure 5). All cells were evaluated by comparison with $\mathrm{IC}_{50}$ values using a CCK-8 assay, revealing that the proliferation of STMN1-, MDR1-, MRP-, TUBB3knockdown cells was significantly diminished compared with the negative-control cells. Moreover, these knockdown cells exhibited significantly higher sensitivity to vincristine than the control cells $(P<0.01$; Table 4$)$.

\section{Discussion}

Although chemotherapy is an important treatment modality for gastric cancer, because of MDR, its effectiveness is significantly reduced as metastasis and recurrence ratios increase. Thus, the reversal of MDR and increase in the sensitivity to chemotherapeutic agents are very important aspects of tumor therapy. YJHD is a traditional Chinese medicine that is an extract comprising 12 species of medicinal plants. Several components have recently been reported to exert 

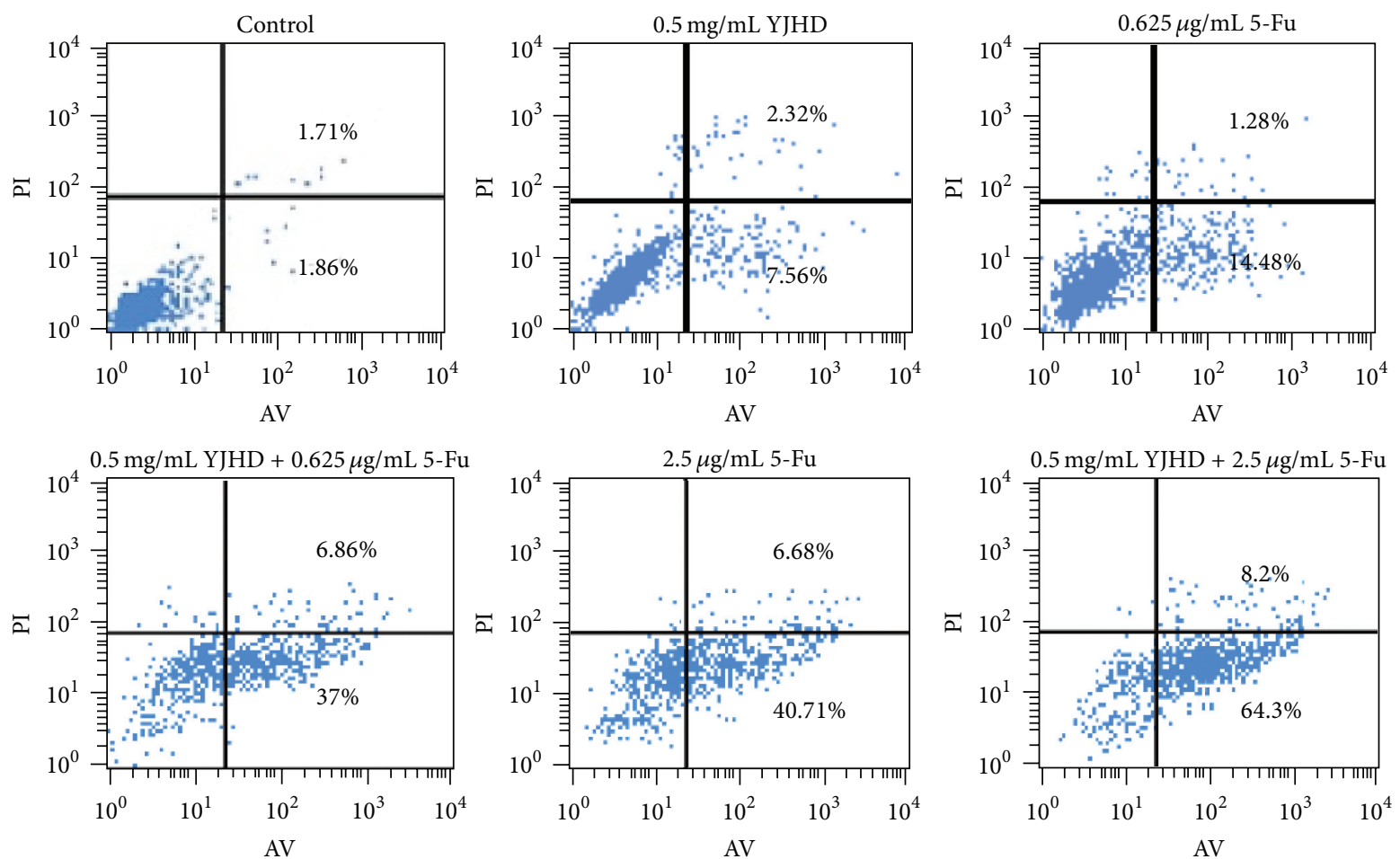

(a)

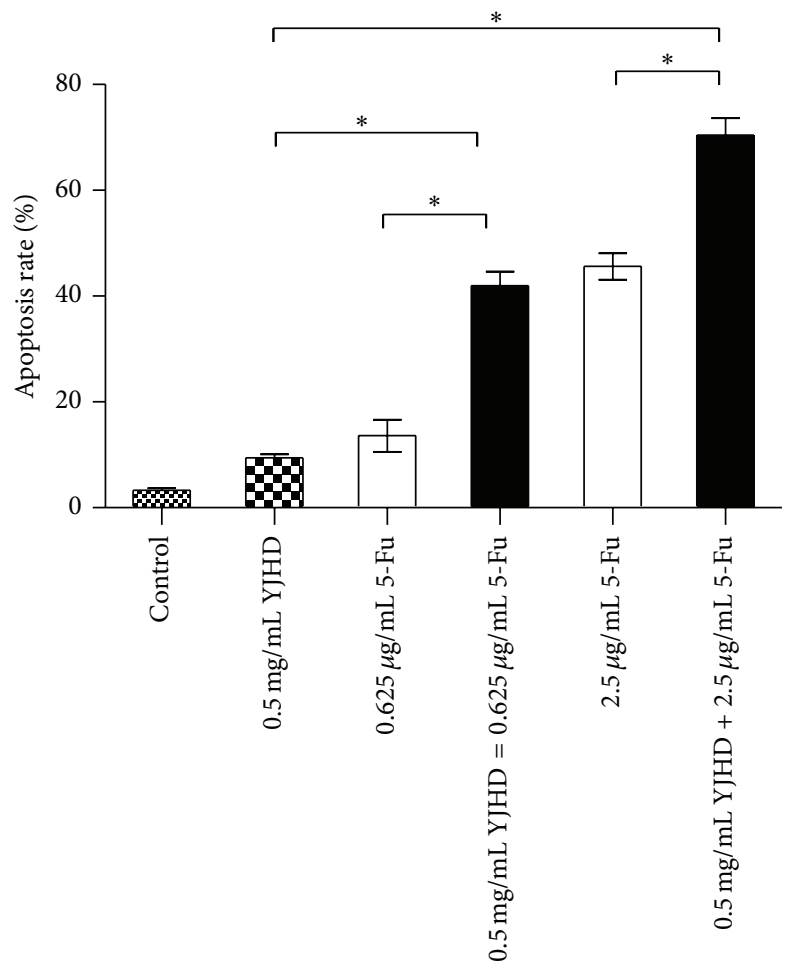

(b)

FIGURE 2: (a) Flow cytometric analysis of apoptosis in SGC7901/VCR cells treated with VCR or 5-Fu, with or without $0.5 \mathrm{mg} / \mathrm{mL}$ YJHD, for $48 \mathrm{~h}$. Analysis of the apoptosis ratio. ${ }^{*} \mathrm{P}<0.05$ versus control. (b) Bar graph of the apoptosis rate. ${ }^{*} \mathrm{P}<0.05$ versus control. 

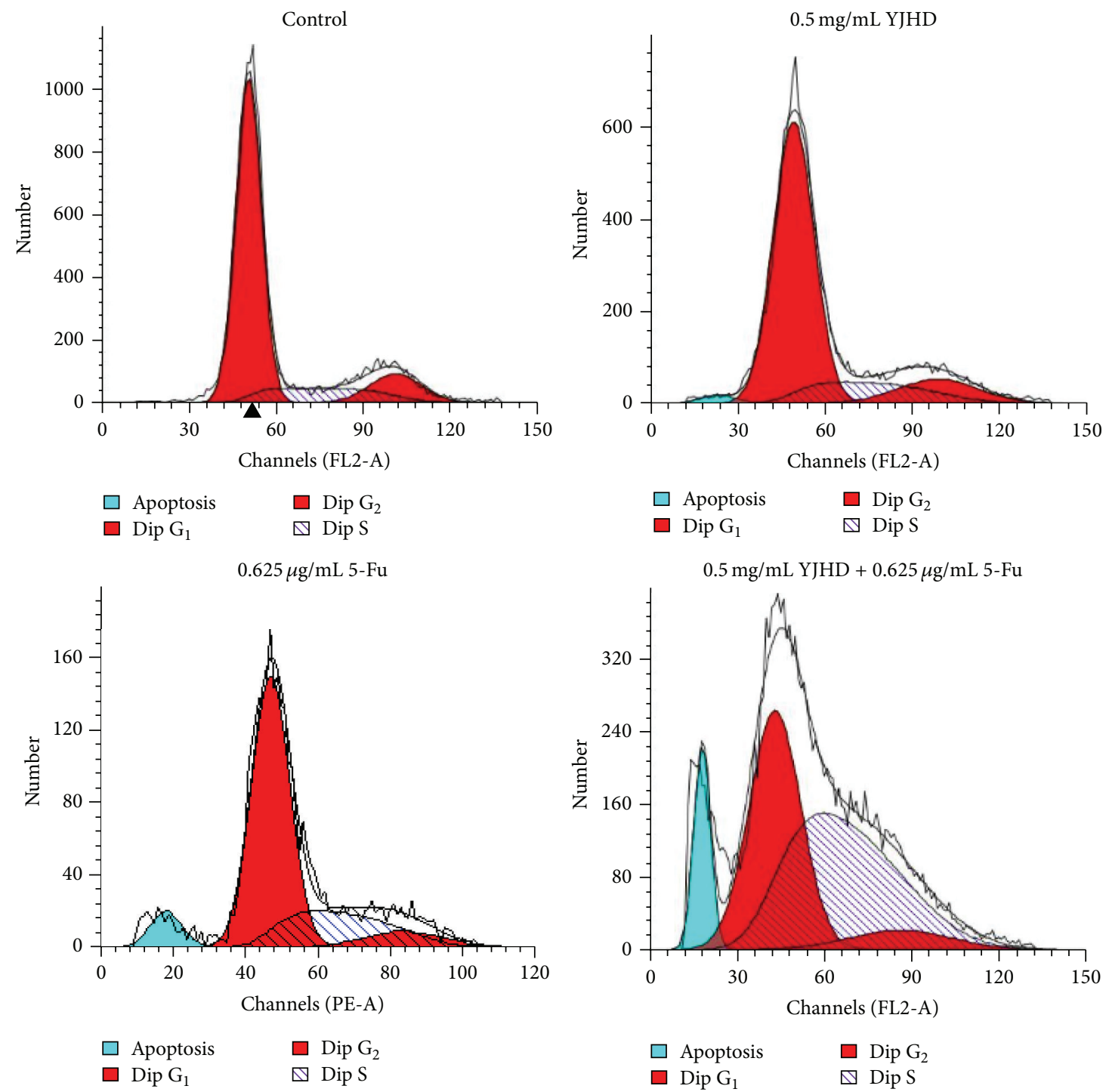

(a)

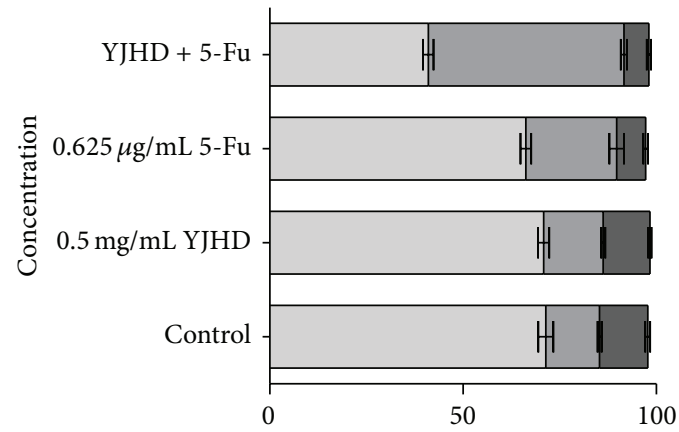

(\%)

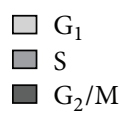

(b)

Figure 3: (a) Cells were cultured with 5-Fu, with or without YJHD $(0.5 \mathrm{mg} / \mathrm{mL})$, for $48 \mathrm{~h}$ and then fixed and stained with PI. The DNA content was analyzed by flow cytometry. $\mathrm{G}_{0} / \mathrm{G}_{1}, \mathrm{G}_{2} / \mathrm{M}$, and $\mathrm{S}$ indicate the cell phases. (b) Each phase was calculated using the ModiFit program. Three duplicated experiments were performed with similar results. 

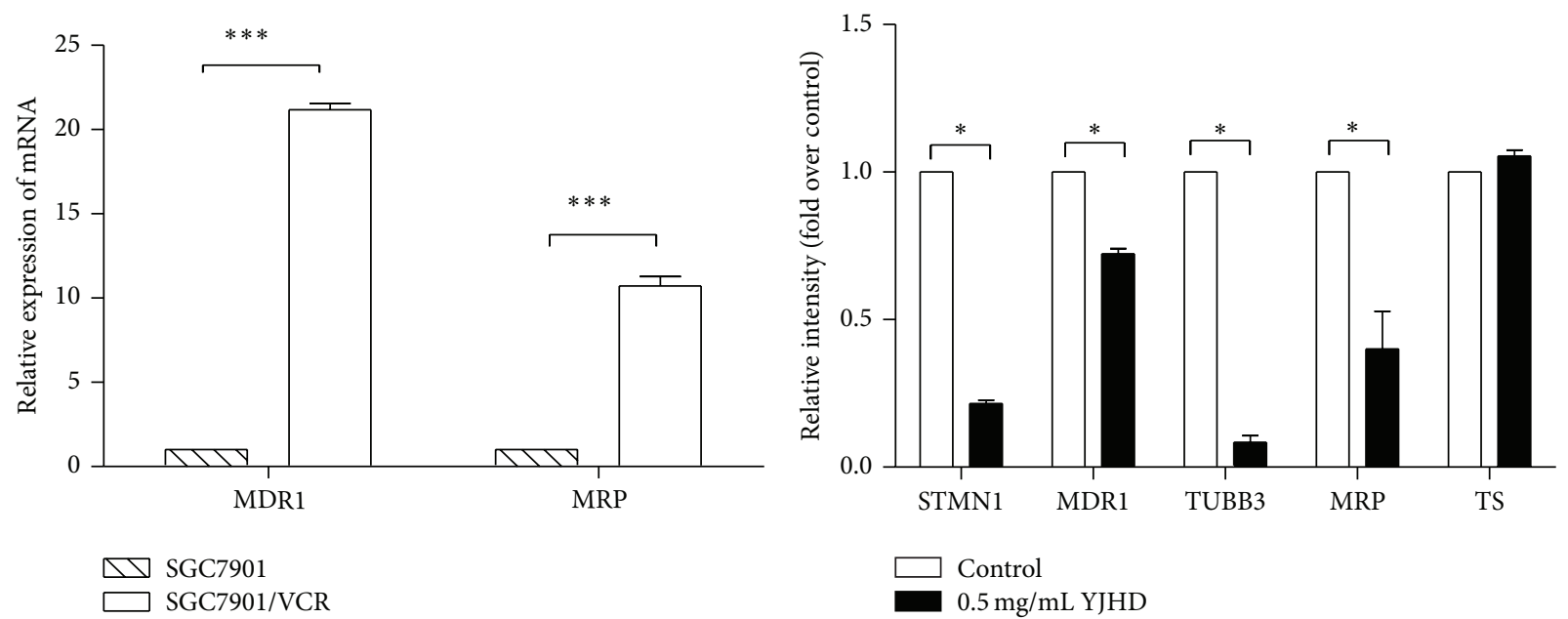

(a)

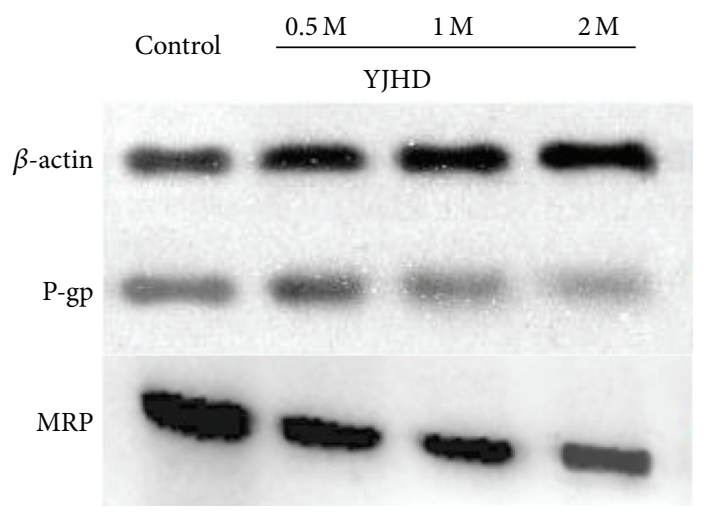

(b)

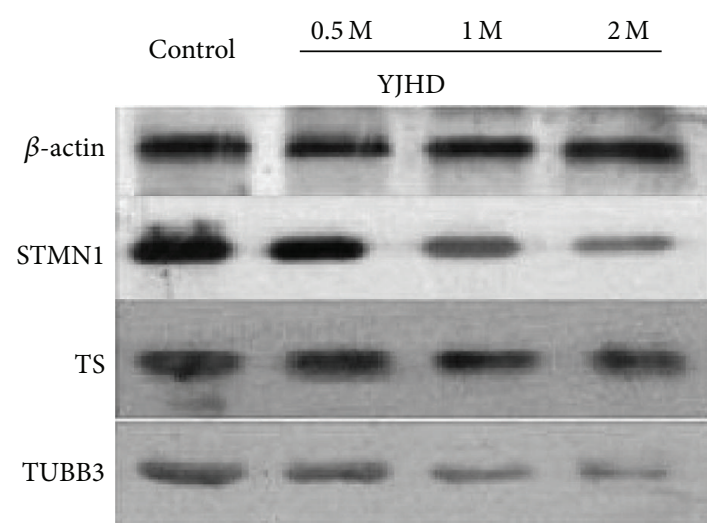

(c)
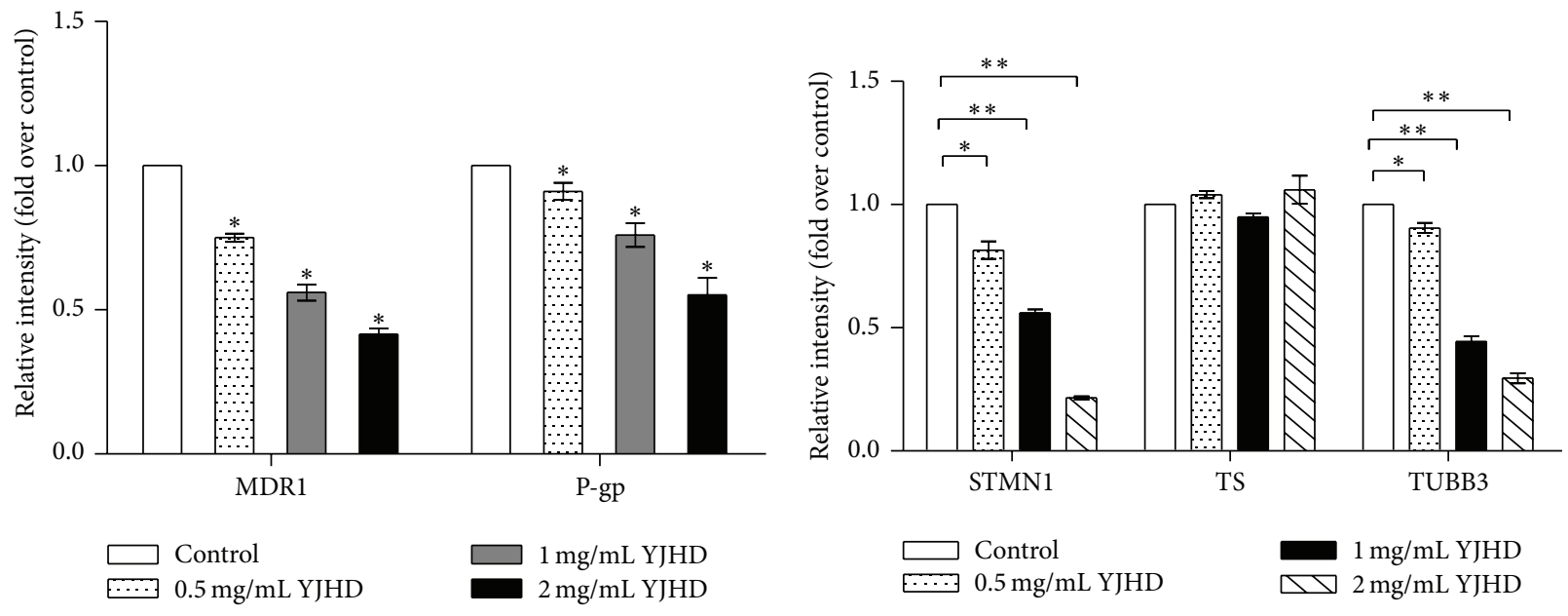

(d)

FIGURE 4: (a) MDR1 and MRP gene expression in SGC7901 and SGC7901/VCR cells. ${ }^{* * *} P<0.01$ versus control. (b) YJHD suppressed the mRNA expression of chemotherapeutic agent resistance-related genes in SGC7901/VCR cells. Fold changes: relative gene expression after treatment with YJHD at $0.5 \mathrm{mg} / \mathrm{mL}$ for $48 \mathrm{~h}$ compared to control. ${ }^{*} P<0.05$ compared with control. (c) Western blot analysis of STMN1, TS, TUBB3, MRP, and P-gp in control cells and cells treated with YJHD at $0.5 \mathrm{mg} / \mathrm{mL}, 1 \mathrm{mg} / \mathrm{mL}$, and $2 \mathrm{mg} / \mathrm{mL}$. (d) Bar graph of the densitometric values of the bands corresponding to MRP, P-gp, STMN1, TS, and TUBB3 normalized relative to $\beta$-actin. ${ }^{*} P<0.05$ versus control, ${ }^{* *} P<0.01$ versus control. 


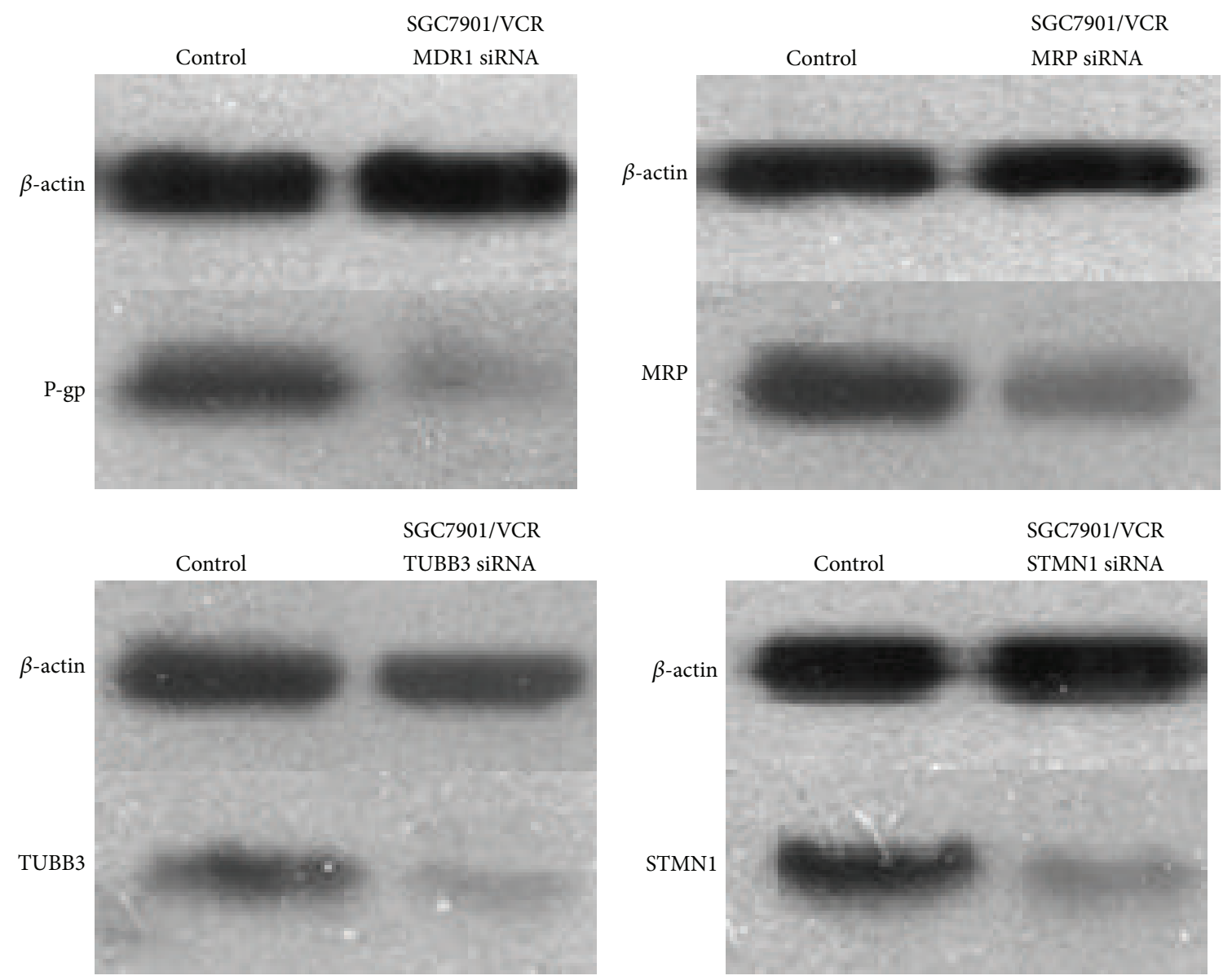

FIGURE 5: STMN1, MDR1, TUBB3, and MRP expression in stably transfected cells. The transfected cells were identified by western blotting. $\beta$-actin was used as an internal control.

antiproliferative effects on several cancer cell lines in vivo and in vitro [14-16], including lung cancer, breast cancer, and colon cancer cells, with several components reducing resistance in breast cancer cell lines [14]. Our previous studies confirmed that YJHD has an antiproliferative effect on the SGC7901 human gastric cancer cell line in vitro [19]. In the present study, we explored the effects of YJHD in an MDR gastric cancer cell line and investigated the underlying mechanism of action. The results of the CCK-8 assay and flow cytometry demonstrated that YJHD dose dependently inhibited proliferation and induced apoptosis in SGC7901/VCR cells $(P<0.05)$. According to the peak plasma concentrations of chemotherapeutic agents in vivo, we observed inhibitory effects of the combination of a low dose of YJHD with 5-Fu and VCR on cell proliferation, showing that low-dose YJHD increased the inhibitory effects.

The influence of YJHD on the expression of intracellular cyclins can cause cell cycle arrest and induce apoptosis in SGC7901 cells [19]. However, our experimental results indicate that a low dose of YJHD does not affect the cell cycle. Our results also suggested that 5-Fu dose dependently induces cell cycle arrest at S phase in SGC7901/VCR cell lines. Moreover, a low concentration of YJHD $(0.5 \mathrm{mg} / \mathrm{mL})$ enhanced the sensitivity of SGC7901/VCR cells to 5-Fu (cell cycle arrest at $\mathrm{S}$ phase).

Furthermore, because several drug-metabolizing genes have been shown to be prognostic markers for gastric cancer therapy, we examined the additional influence of YJHD on their mRNA and protein expression.

Microtubules are composed of tubulin dimers and interact with a variety of microtubule-associated proteins [20]. Studies in lung cancer have shown that high expression levels of brain-specific TUBB3 are associated with vincristine resistance in a preclinical setting, which has been further confirmed in patients with advanced NSCLC [21]. STMN1 has been shown to regulate the dynamics of the microtubules that compose the mitotic spindle, and STMN1 overexpression leads to the resistance to antimicrotubule agents [22]. A decreased sensitivity of breast cancer cells to Vinca alkaloids and Taxol in response to the overexpression of the microtubule-associated protein STMN1 was reported by Alli et al. [22], and a high TS expression level was reported to be associated with resistance to 5-Fu therapy and a poor clinical outcome [23]. A meta-analysis [24] demonstrated that the TS expression level should be considered one of the most important markers of the 5-Fu response. A previous study 
demonstrated that P-gp is overexpressed in H. pylori positive patients, particularly in patients who do not respond to eradication therapy [5], and a causal link has been reported between MRP and P-gp activity, which may have implications for MDR in tumors in which MRP is overexpressed. Our data also indicate that YJHD downregulated the expression of MRP, TUBB3, STMN1, MDR1 mRNA, and protein, though the expression of TS was not significantly affected. In this study, we found that the capacity of the Chinese medicine to reverse resistance to fluorouracil is stronger than that of vincristine. Accordingly, we suggest that the drug-induced resistance mechanism of the latter is more complex, with other mechanisms of resistance in addition to an increase in the expression of four genes.

We then used RNAi technology to knock down the expression of these four genes and found that the sensitivity to chemotherapy drugs by multidrug-resistant cells was notably increased, confirming our results.

To our knowledge, the present study is the first to demonstrate the effects of YJHD on an MDR human gastric cancer cell line. YJHD inhibited proliferation, induced apoptosis, circumvented MDR, and increased sensitivity to chemotherapeutic agents in the P-gp-overexpressing gastric cancer cell line SGC7901/VCR. The effects of YJHD may be attributed to the downregulation of the expression of MDR1/P-gp, MRP, TUBB3, and STMN1, thus weakening the level of P-gp-mediated MDR and increasing the sensitivity of SGC7901/VCR cells to chemotherapy.

The present study suggests that the use of chemotherapeutic agents in combination with YJHD as a chemosensitizer or adjuvant may be helpful for the treatment of gastric cancer. We also found that chemotherapy together with RNA interference appears to exert a promising therapeutic effect. Although clinical application needs to be evaluated, these findings provide an intriguing possibility for future cancer therapy.

\section{Conflict of Interests}

The authors declare that there is no conflict of interests regarding the publication of this paper.

\section{Authors' Contribution}

Wei-Bing Li and Yang Li contributed equally to this work.

\section{Acknowledgments}

This project was funded by the State Administration of Traditional Chinese Medicine of the People' Republic of China, the National Traditional Chinese Medicine Clinical Research Base Construction of Special Topic Research no. JDZX2012090, and Jiangsu Province Hospital of TCM.

\section{References}

[1] J. Ferlay, H. R. Shin, F. Bray et al., GLOBOCAN 2008: Cancer Incidence and Mortality Worldwide: IARC Cancer Base No 10 Lyon, France, International Agency for Research on Cancer, Lyon, France, 2010.
[2] X. Sun, R. Mu, Y. Zhou et al., "1990-1992 mortality of stomach cancer in China," Chinese Journal of Oncology, vol. 24, no. 1, pp. $4-8,2002$.

[3] S. Labialle, L. Gayet, E. Marthinet, D. Rigal, and L. G. Baggetto, "Transcriptional regulators of the human multidrug resistance 1 gene: recent views," Biochemical Pharmacology, vol. 64, no. 5-6, pp. 943-948, 2002.

[4] C. Mignogna, S. Staibano, V. Altieri et al., "Prognostic significance of multidrug-resistance protein (MDR-1) in renal cancer cell carcinomas: a five year follow-up analysis," BMC Cancer, vol. 6, article 293, 2006.

[5] X.-Q. Yu, C. C. Xue, G. Wang, and S.-F. Zhou, "Multidrug resistance associated proteins as determining factors of pharmacokinetics and pharmacodynamics of drugs," Current Drug Metabolism, vol. 8, no. 8, pp. 787-802, 2007.

[6] E. K. Fetisova, A. V. Avetisyan, D. S. Izyumov, M. V. Korotetskaya, B. V. Chernyak, and V. P. Skulachev, "Mitochondriatargeted antioxidant SkQR1 selectively protects MDR (Pgp 170)negative cells against oxidative stress," FEBS Letters, vol. 584, no. 3, pp. 562-566, 2010.

[7] G. Nardone, A. Rocco, D. Vaira et al., "Expression of COX-2, mPGE-synthase ${ }_{1}$, MDR-1 (P-gp), and Bcl- $\mathrm{x}_{L}$ : a molecular pathway of $H$ pylori-related gastric carcinogenesis," The Journal of Pathology, vol. 202, no. 3, pp. 305-312, 2004.

[8] Y. Zhang, X. Qu, X. Hu et al., "Reversal of P-glycoproteinmediated multi-drug resistance by the E3 ubiquitin ligase Cbl$\mathrm{b}$ in human gastric adenocarcinoma cells," The Journal of Pathology, vol. 218, no. 2, pp. 248-255, 2009.

[9] H.-W. Xu, L. Xu, J.-H. Hao, C.-Y. Qin, and H. Liu, "Expression of P-glycoprotein and multidrug resistance-associated protein is associated with multidrug resistance in gastric cancer," The Journal of International Medical Research, vol. 38, no. 1, pp. 3442, 2010.

[10] W. Liu, Y.-H. Yu, X.-N. Ouyang et al., "Clinical significance of Pglycoprotein and topoisomerase II expression in gastric cancer," The World Chinese Journal of Digestology, vol. 18, no. 34, pp. 3640-3647, 2010.

[11] V. Vallacchi, M. Daniotti, F. Ratti et al., "CCN3/nephroblastoma overexpressed matricellular protein regulates integrin expression, adhesion, and dissemination in melanoma," Cancer Research, vol. 68, no. 3, pp. 715-723, 2008.

[12] M. Cervello and G. Montalto, "Cyclooxygenases in hepatocellular carcinoma," World Journal of Gastroenterology, vol. 12, no. 32, pp. 5113-5121, 2006.

[13] L. Yang and D. D. Wei, "Reversal effects of traditional Chinese herbs on multidrug resistance in cancer cells," Phytotherapy Research, vol. 26, no. 4, pp. 562-567, 2012.

[14] L. Yang, D. D. Wei, Z. Chen, J. S. Wang, and L. Y. Kong, "Reversal of multidrug resistance in human breast cancer cells by Curcuma wenyujin and Chrysanthemum indicum," Phytomedicine, vol. 18, no. 8-9, pp. 710-718, 2011.

[15] G. Gu, I. Barone, L. Gelsomino et al., "Oldenlandia diffusa extracts exert antiproliferative and apoptotic effects on human breast cancer cells through ER $\alpha /$ Sp1-mediated p53 activation," Journal of Cellular Physiology, vol. 227, no. 10, pp. 3363-3372, 2012.

[16] J. Sun, S. Wang, and Y.-H. Wei, "Reproductive toxicity of Rhizoma Sparganii (Sparganium stoloniferum Buch.-Ham.) in mice: mechanisms of anti-angiogenesis and anti-estrogen pharmacologic activities," Journal of Ethnopharmacology, vol. 137, no. 3, pp. 1498-1503, 2011. 
[17] D. M. Dykxhoorn, D. Palliser, and J. Lieberman, "The silent treatment: SiRNAs as small molecule drugs," Gene Therapy, vol. 13, no. 6, pp. 541-552, 2006.

[18] P. B. Mullan, J. E. Quinn, P. M. Gilmore et al., "BRCA1 and GADD45 mediated G2/M cell cycle arrest in response to antimicrotubule agents," Oncogene, vol. 20, no. 43, pp. 61236131, 2001.

[19] S. Peng and G. Ting-Jie, "Jian Pi Yang Wei compound on human gastric cancer cell line SGC7901 experiment on growth inhibition and apoptosis," Jiangsu Journal of Traditional Chinese Medicine, vol. 45, no. 3, pp. 70-72, 2013.

[20] P. Sève, S. Isaac, O. Trédan et al., "Expression of class iii $\beta$ tubulin is predictive of patient outcome in patients with nonsmall cell lung cancer receiving vinorelbine-based chemotherapy," Clinical Cancer Research, vol. 11, no. 15, pp. 5481-5486, 2005.

[21] Y. Zhang, H. Yang, J. Liu et al., "High expression levels of class IIIbeta-tubulin in resected non-small cell lung cancer patients are predictive of improved patient survival after vinorelbinebased adjuvant chemotherapy," Oncology Letters, vol. 6, no. 1, pp. 220-226, 2013.

[22] E. Alli, J.-M. Yang, J. M. Ford, and W. N. Hait, "Reversal of stathmin-mediated resistance to paclitaxel and vinblastine in human breast carcinoma cells," Molecular Pharmacology, vol. 71, no. 5, pp. 1233-1240, 2007.

[23] C. Aschele, S. Lonardi, and S. Monfardini, "Thymidylate synthase expression as a predictor of clinical response to fluoropyrimidine-based chemotherapy in advanced colorectal cancer," Cancer Treatment Reviews, vol. 28, no. 1, pp. 27-47, 2002.

[24] S. Popat, A. Matakidou, and R. S. Houlston, "Thymidylatesynthase expression and prognosis in colorectal cancer: a systematic review and meta-analysis," Journal of Clinical Oncology, vol. 22, no. 3, pp. 529-536, 2004. 


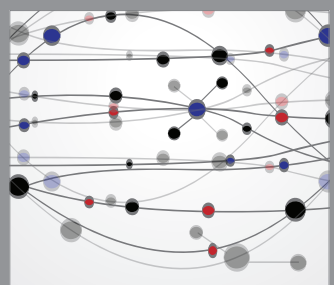

The Scientific World Journal
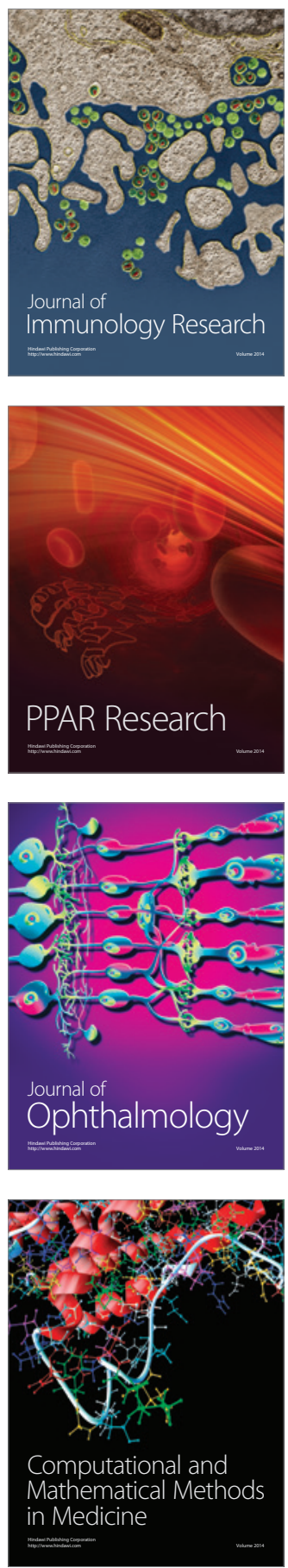

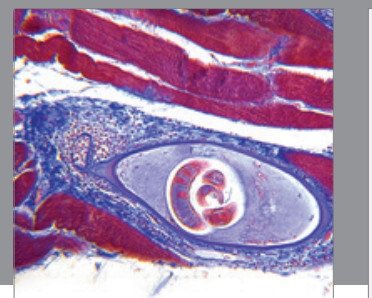

Gastroenterology

Research and Practice
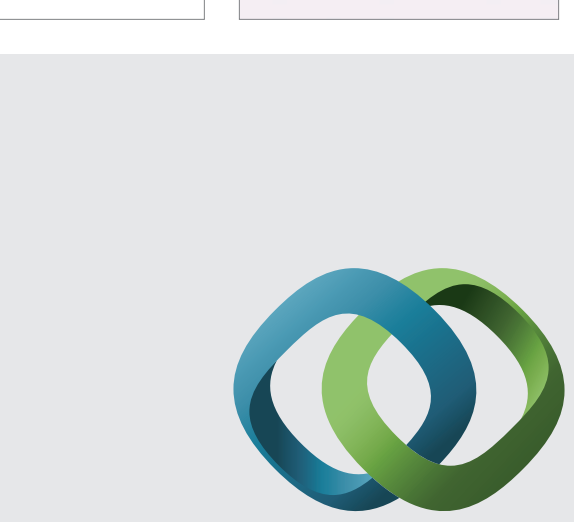

\section{Hindawi}

Submit your manuscripts at

http://www.hindawi.com
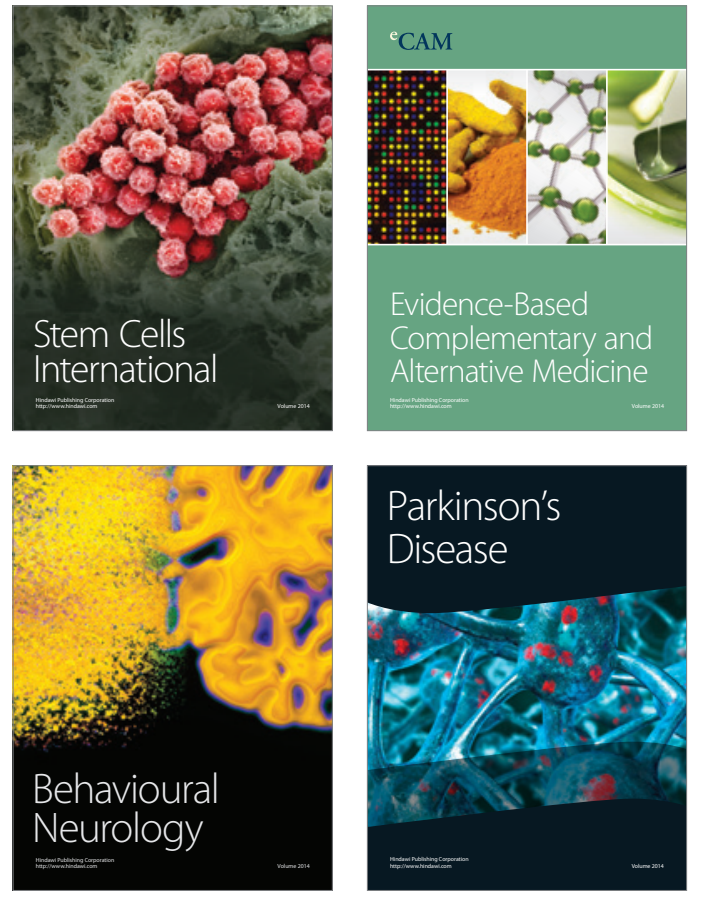
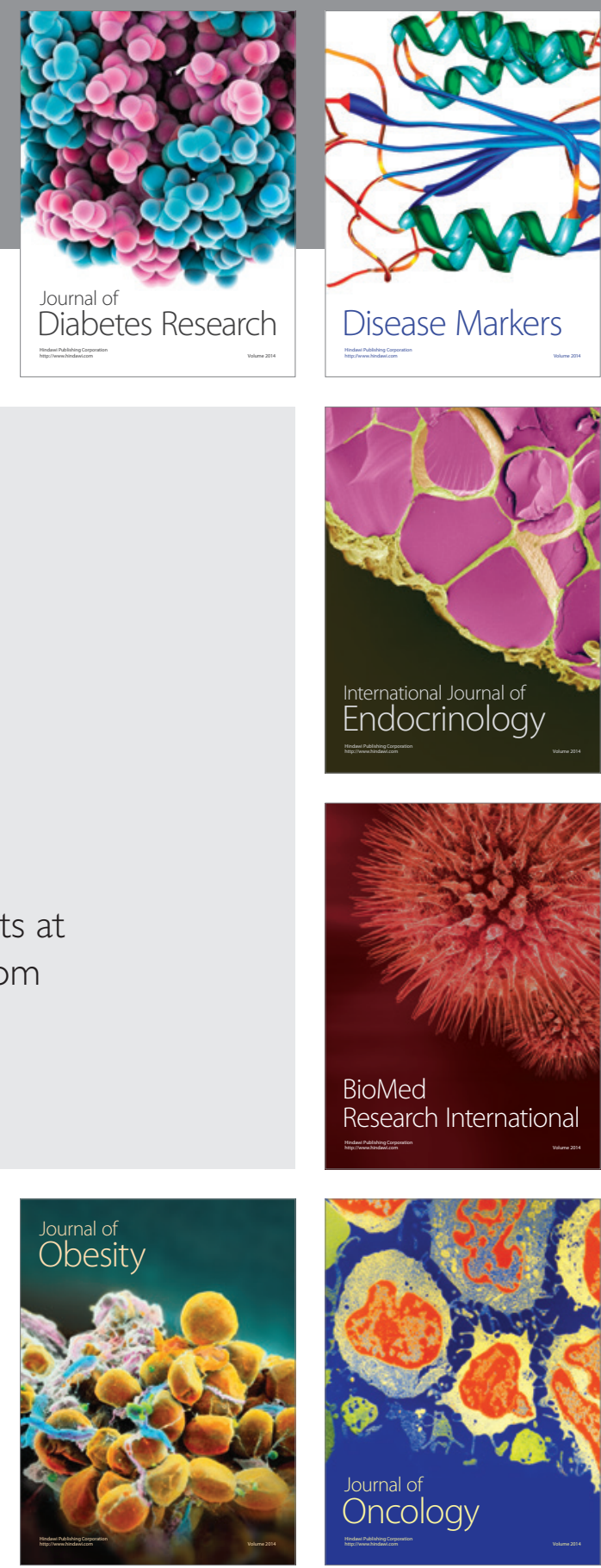

Disease Markers
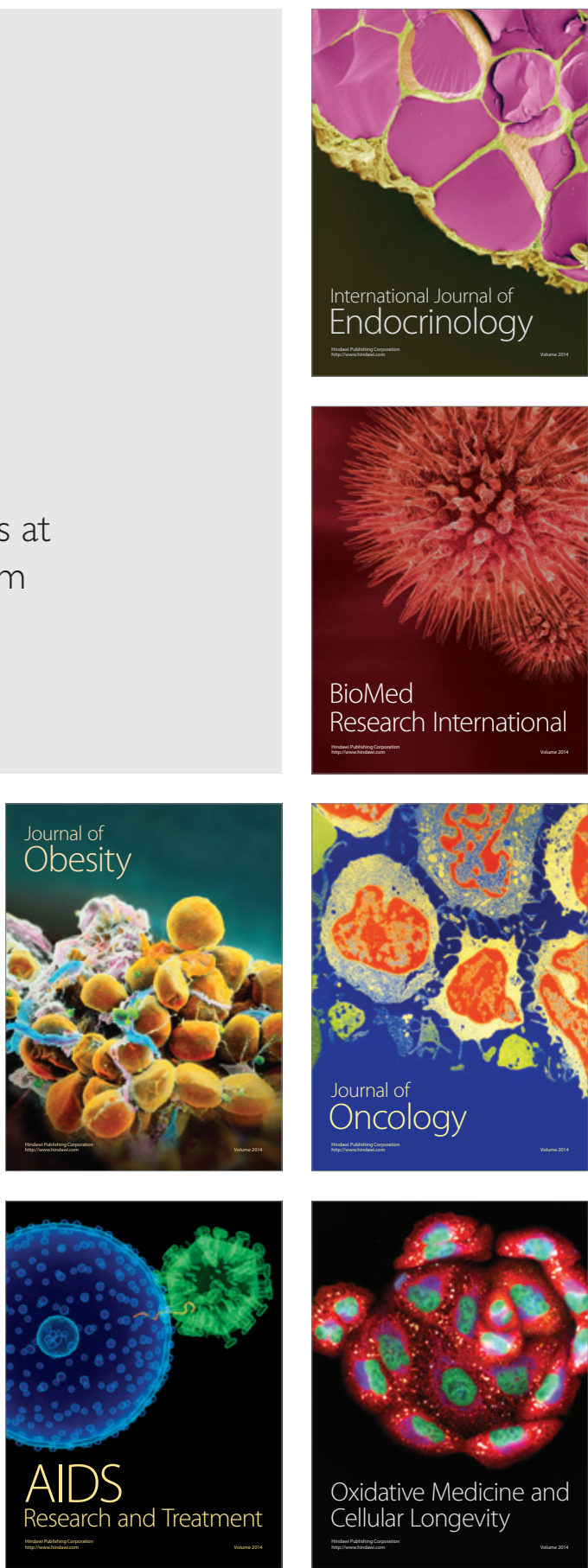